\title{
Factors Associated with Early Marriage in Sleman, Yogyakarta
}

\author{
Nurul Husna1), Argyo Demartoto²), SupriyadiHari Respati3) \\ 1) Masters Program in Public Health, SebelasMaret University, Surakarta \\ 2) Faculty of Social and Political Sciences, SebelasMaret University, Surakarta \\ 3) Department of Obstetrics and Gynecology, Dr. Moewardi Hospital, Surakarta
}

\begin{abstract}
Background: Early marriageis a complex social issue with indirect implication on the quality of family. Early marriage can indirectly contribute to increasing maternal mortality rate and infant mortality rate. There were 135 early marriage cases reported in Sleman district in 2013, 150 cases in 2014, and 123 cases in 2015. The purpose of this study was to analyze factors associates with the incident of early marriage in Sleman, Yogyakarta.

Subjects and Method: This was an analytic observational study with case control design conducted in Sleman, Yogyakarta, Central Java, in Indonesia, August to November 2016.A total sample of 120 study subjects consisting of 40 early married young couples and 80 in time married young couples, was selected for this study, by purposive sampling. The dependent variable was early marriage. The indipendent variables included family disharmony, emotional insecurity, promiscuity tendency, unintended pregnancy, maternal education, family social economic class, parent perception of early marriage, and local culture regarding early marriage. The data were collected by questionnaire and document review at the office of religious affairs. The data were analyzed by path analysis using STATA 13 .

Results: There were direct relationships between unintended pregnancy $(b=3.40$; CI95\%= 1.08-5.71; $\mathrm{p}=0.004)$, income $(\mathrm{b}=-1.58 ; \mathrm{CI} 95 \%=0.58 \mathrm{sd} 2.18 ; \mathrm{p}=0.001)$,promiscuity tendency $(b=1.93 ; \quad C I 95 \%=-3.11-0.06 ; p=0.042)$, parent perception of early marriage $(b=2.75$; $\mathrm{CI} 95 \%=0.49-5.02 ; \mathrm{p}=0.017)$, local culture regarding early marriage $(\mathrm{b}=5.62 ; \mathrm{CI} 95 \%=2.63-$ 8.62; $\mathrm{p}<0.001)$ and the incidence of early marriage. There were indirect relationsh e. ips between family disharmony, emotional security, promiscuity tendency, maternal education, and incident of early marriage.

Conclusion: There were direct relationships between unintended pregnancy, social economic class, promiscuity tendency, parent perception of early marriage, local culture regarding early marriage and the incidence of early marriage.
\end{abstract}

Keywords: Early marriage, family disharmony, unintended early married, local cultur

\section{Correspondence:}

Nurul Husna. Masters Program in Public Health,Sebelas Maret University, Surakarta.

\section{LATAR BELAKANG}

Pernikahan dini adalah segala bentuk pernikahan yang terjadi sebelum anak berusia 18 tahun. Kebanyakan pernikahan dini karena persetujuan dari orang tua dan lebih umum terjadi pada perempuan muda diban dingdengan anak laki-laki(UNICEF, 2013; AFN, 2016).

Penentuan batas minimum usia pernikahan sangat penting, karena secara ti-

e-ISSN: 2549-1172(online) dak langsung mempengaruhi kualitas dalam kehidupan berumah tangga.Dari sisi kesehatan, salah satu hal yang menyumbang tingginya Angka Kematian Ibu (AKI) dan Angka Kematian Bayi (AKB) adalah rendahnya usia menikah pertama yang se makin meningkat di Indonesia.Menurut Survei Demografi dan Kesehatan Indonesia (SDKI) tahun 2012, angka kematian ibu meningkat menjadi 359 dari sebelumnya 
Journal of Health Promotion and Behavior (2016), 1(2): 87-98

https://doi.org/10.26911/thejhpb.2016.01.02.04

228 per 100,00o kelahiran hidup pada tahun 2007. Semakin rendah usia pernikahan pertama maka semakin besar risiko yang dihadapi selama kehamilan, persalinan dan nifas baik keselamatan bagi ibu maupun anaknyakarena belum matangnya organ reproduksi ibu (Prakarsa, 2013; Pusdatin Kemenkes, 2014).

Menurut United Nations Development Economic and Social Affairs (UNDESA), Indonesia merupakan negara ke-37 dengan jumlah pernikahan dini terbanyak di dunia.Sedangkan dalam konteks regional ASEAN Indonesia menempati urutan kedua terbanyak setelah Kamboja (Mutyaba, 2011;UNDESA, 2011).

Daerah Istimewa Yogyakarta merupakan daerah berkembangnya kebudayaan Jawa selain Surakarta. Dalam masyarakat Jawa membicarakan masalah seksualitas dianggap tabu dan menjunjung tinggi nilai virginitas seorang perempuan (Koentjaraningrat, 1994). Namun realitas yang ada di Kabupaten Sleman, angka pernikahan dini naik dari tahun 2013 terdapat 135 perkara menjadi 150 perkara pada tahun 2014, kemudian tahun 2015 turun menjadi 123 perkara.Sebagian besar pasangan yang menikah karena hamil lebih dulu. Usia yang mengajukan dispensasi pernikahan dari tahun ke tahun juga semakin muda yaitu menyentuh usia 13-15 tahun (Kasi Bimas Islam Kantor kementerian Agama Kabupaten Sleman, 2016).

Menurut penelitian Jones dan Gubhaju (2008), pernikahan dini di Indonesia secara frekuen merefleksikan pernikahan dini yang diatur atau direncanakan karena kehamilan diluar nikah.Talcott Parsonss melalui teori struktural fungsional menyebutkan bahwa tindakan manusia dipengaruhi oleh empat sistem yaitu sistem budaya, sosial, kepribadian dan organisme atau aspek bilogis dari manusia itu sendiri.
Kehamilan diluar nikah paling besar dipengaruhi oleh pola asuh orang tua dan keadaan disharmoni keluarga.Disharmoni keluarga menyebakan anak mengalami depresi atau emotional insecurity. Dalam keadaan emotional insecurity, anak akan cenderung bersikap agresif sehingga melakukan pergaulan bebas. Pergaulan bebas memiliki hubungan yang signifikan dengan terjadinyakehamilantidakdiinginkan

(Omarsari dan Djuwita, 2008).

Menurut BKKBN (2012) dan UNFPA (2012) faktor terjadinya pernikahan dini di Indonesia karena anggapan negatif terhadap perawan tua jika menikah di usia lebih dari 17 tahun, atau memang karena kebiasaan masyarakat Indonesia menikah di usia sekitar 14-16 tahun. Selain itu, faktor ekonomi rendah juga turut mendorong terjadinya perjodohan di Indonesia.

Upaya dalam penurunan angka pernikahan dini telah dilakukan oleh pemerintah Indonesia. Melalui SDG's goal kelima tentang penyataraan gender dan pemberdayaan perempuan dan menghilangkan praktik berbahaya termasuk pernikahan dini dan pernikahan paksa. Program GenRe goes to school dan goes to campus BKKBN dan Interkoneksi Program

Bina Remaja Keluarga Sakinah dalam konteks Kabupaten.Namun, belum menun jukkan hasil yang maksimal (BKKBN, 2010; Kasi Bimas Islam Kantor kementerian Agama Kabupaten Sleman, 2016).

Berdasarkan uraian di atas dapat disimpulkan bahwa pernikahan dini pada remaja di Indonesia merupakan masalah penting untuk dilakukan tindakan penurunan angka pernikahan dini dari berbagai faktor dengan mempertimbangkan penyebab langsung dan tidak langsung terjadinya pernikahan dini.

Tujuan penelitian ini adalah menganalisis hubungan antara disharmoni keluarga, emotional insecurity, sikap kecen- 
derungan melakukan pergaulan bebas, ke hamilan tidak diinginkan, pendidikan ibu, tingkat pendapatan, persepsi orang tua tentang menikah dini, budaya lokal me nikah dini dan terjadinya pernikahan dini dengan pendekatan path analysis.

\begin{tabular}{l}
\hline SUBJEK DAN METODE \\
\hline Desain penelitian yang digunakan \\
adalahsurvei korelasional dengan pende- \\
katan case control. Waktu pelaksanaan \\
pada bulan Agustus sampai November 2016 \\
di Kabupaten Sleman, Daerah Istimewa \\
Yogyakarta, Indonesia. Variabel dalam pe- \\
nelitian adalah disharmoni keluarga, emo- \\
tional insecurity, sikap kecenderungan \\
melakukan pergaulan bebas, kehamilan \\
tidak diinginkan, pendidikan ibu, tingkat \\
pendapatan, persepsi orang tua tentang \\
menikah dini, budaya lokal menikah dini
\end{tabular}

dan pernikahan dini pada remaja. Populasi dalam penelitian adalah remaja perempuan di wilayah Kabupaten Sleman. Sampel se banyak 120 subjek dipilih secara purposive sampling dengan pencuplikan area, dengan kelompok kasus 40 subjek dan kelompok kontrol 80 subjek. Teknik pengumpulan data menggunakan data KUA se-Kabupaten Sleman dan kuesioner.Data dianalisis denganpath analysisyang menggunakan program Stata 13.

\section{HASIL \\ 1. Karakteristik subjek penelitian}

Karakteristik subjek penelitian pada tabel 1 menunjukkan bahwa dari 120 subjek pene litian memiliki distribusi yang berbedabeda. Deskripsi variabel penelitian dijelaskan berdasarkan karakteristik, kriteria, frekuensi, persentase (\%), mean dan SD.

Tabel 1. Karakteristik subjek penelitian

\begin{tabular}{|c|c|c|c|c|}
\hline \multirow[t]{2}{*}{ Kriteria } & \multicolumn{2}{|c|}{ Menikah dini } & \multicolumn{2}{|c|}{ Tidak menikah dini } \\
\hline & n(\%) & $\operatorname{Mean}(\mathbf{s d})$ & n(\%) & Mean(sd) \\
\hline Umur Remaja & & $18.85(1.21)$ & & $18.49(1.66)$ \\
\hline (12 hingga $<20$ tahun) & $40(33.33)$ & & & \\
\hline \multicolumn{5}{|l|}{ Pendidikan Remaja } \\
\hline Rendah $(<$ SMA $)$ & $29(24.2)$ & & o & \\
\hline Tinggi ( $\geq$ SMA) & $11(9.2)$ & & $55(45.8)$ & \\
\hline Pelajar & o & & $55(45.8)$ & \\
\hline Umur Ibu & & $45.7(8.92)$ & & $47 \cdot 39(5 \cdot 38)$ \\
\hline 30-45 tahun & $19(15.8)$ & & $23(19.2)$ & \\
\hline 46-6o tahun & $20(16.7)$ & & $56(46.7)$ & \\
\hline$>60$ tahun & $1(0.8)$ & & $1(0.8)$ & \\
\hline \multicolumn{5}{|l|}{ Pekerjaan Ibu } \\
\hline Tidak bekerja & $14(11.67)$ & & $41(34.16)$ & \\
\hline Bekerja & $26(21.67)$ & & $39(32.5)$ & \\
\hline Umur ibu saat menikah & & $19.43(2.93)$ & & $23.26(2.98)$ \\
\hline$<20$ tahun & $22(18.3)$ & & $5(4.2)$ & \\
\hline$\geq 20$ tahun & $18(15.0)$ & & $75(62.5)$ & \\
\hline
\end{tabular}

Perbandingan subjek penelitian yang menikah dinidan tidak menikah dini 1:2 yaitu 33.3\%:66.7\%. Sebagian besar subjek penelitian mengalami disharmoni keluarga rendah yaitu 70 subjek penelitian (58.3\%), mengalami emotional insecurity rendah 
Journal of Health Promotion and Behavior (2016), 1(2): 87-98

https://doi.org/10.26911/thejhpb.2016.01.02.04

yaitu 78 subjek penelitian (65\%), sikap kecenderungan melakukan pergaulan bebas rendah yaitu 63 subjek penelitian (52.5\%), tidak mengalami KTD yaitu 83 subjek penelitian (69.2\%), pendidikan ibu rendah yaitu 70 subjek penelitian (58.3\%), memiliki tingkat pendapatan tinggi yaitu 70 subjek penelitian (58.3\%), Persepsi ibu tidak setuju tentang menikah dini yaitu 64 subjek penelitian (53.3\%), tidak budaya lokal menikah dini yaitu 64 subjek penelitian (53.3\%).

\section{Analisis Bivariat}

Variabel dalam penelitian yaitu disharmoni keluarga, emotional insecurity, sikap kecenderungan melakukan pergaulan bebas, kehamilan tidak diinginkan, pendidikan ibu, tingkat pendapatan, persepsi orang tua tentang menikah dini, budaya lokal menikah dini dan status mernikah dini. Metode yang digunakan adalah uji chi-square.

Tabel 2. Hasil analisis bivariat

\begin{tabular}{|c|c|c|c|c|}
\hline \multirow[b]{2}{*}{ Variabel Independen } & \multirow[b]{2}{*}{ OR } & \multirow[b]{2}{*}{$\mathbf{p}$} & \multicolumn{2}{|c|}{ CI (95\%) } \\
\hline & & & $\begin{array}{c}\text { Batas } \\
\text { Atas } \\
\end{array}$ & $\begin{array}{c}\text { Batas } \\
\text { Bawah }\end{array}$ \\
\hline Disharmoni keluarga & 7.41 & $<0.001$ & 3.15 & 17.4 \\
\hline Emotional insecurity & 3.67 & 0.001 & 1.64 & 8.19 \\
\hline Sikap kecenderungan melakukan pergaulan bebas & 4.90 & $<0.001$ & 2.13 & 11.25 \\
\hline Kehamilan tidak diinginkan & 14.54 & $<0.001$ & 5.7 & 37.08 \\
\hline Pendidikan ibu & 17.57 & $<0.001$ & 4.99 & 61.8 \\
\hline Tingkat Pendapatan & 11.06 & $<0.001$ & 4.48 & 27.29 \\
\hline Persepsi orang tua & 14.94 & $<0.001$ & 5.51 & 40.49 \\
\hline Budaya lokal menikah dini & 144.5 & $<0.001$ & 18.5 & 1129 \\
\hline
\end{tabular}

\section{Path Analysis}

Path analysis menjelaskan tentang faktor yang berhubungan langsung dan tidak langsung terkait penyebab terjadinya pernikahan dini.Berikut adalah Gambar 1 spe- sifikasi model path analysis.Dengan nilai degree of freedom $(\mathrm{df})=26$ berarti overidentified yang berarti path analysis bisa dilakukan.

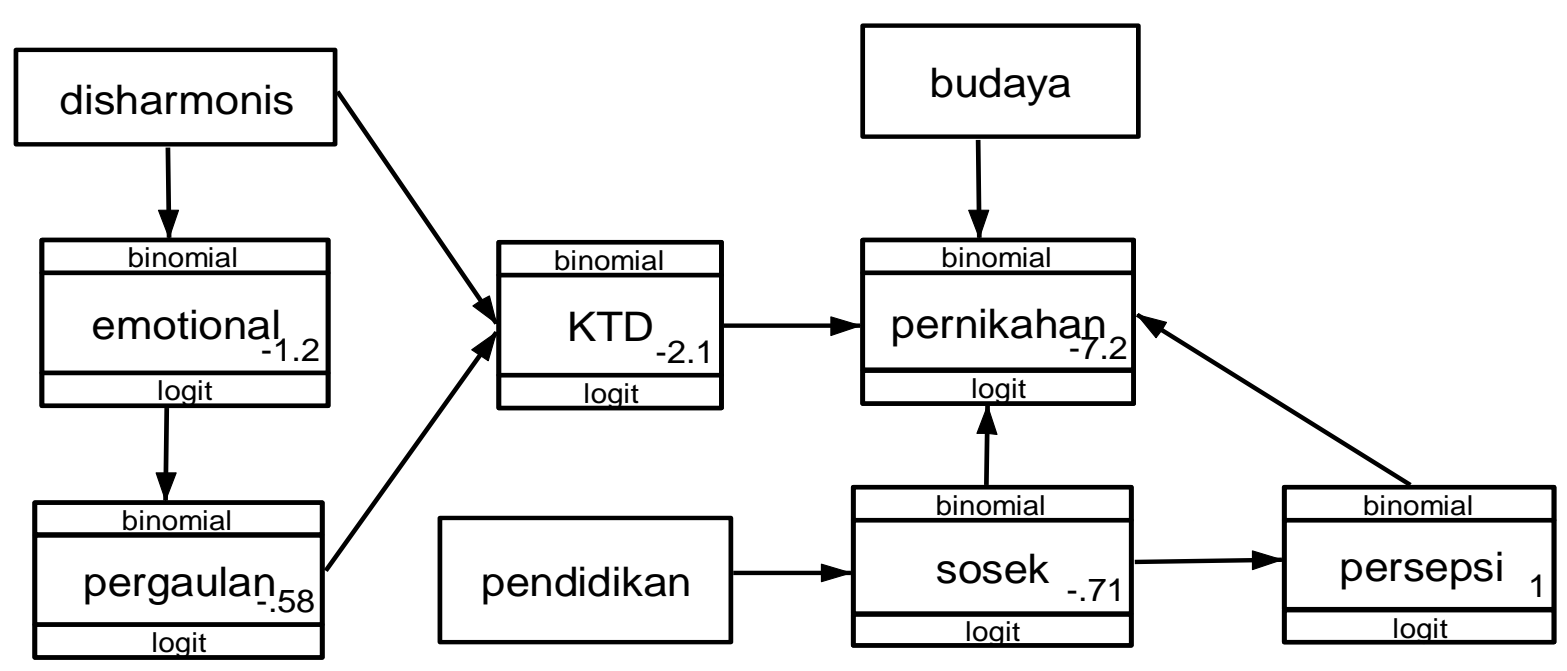

Gambar 1. Identifikasi model path analysis 
Tabel 3.Hasil path analysis faktor yang menyebabkan terjadinyapernikahan dini

\begin{tabular}{|c|c|c|c|c|}
\hline \multirow{2}{*}{$\begin{array}{c}\text { Hubungan Variabel dependen dan } \\
\text { independen }\end{array}$} & \multirow{2}{*}{$\begin{array}{l}\text { Koef } \\
\text { jalur }\end{array}$} & \multicolumn{2}{|c|}{ CI 95\% } & \multirow{2}{*}{$\mathbf{p}$} \\
\hline & & Batas Bawah & Batas Atas & \\
\hline \multicolumn{5}{|l|}{ Direct } \\
\hline \multicolumn{5}{|l|}{ Pernikahan dini $\leftarrow$} \\
\hline Kehamilan Tak Diinginkan (KTD) & 3.40 & 1.08 & 5.71 & $0.004^{*}$ \\
\hline Budaya lokal menikah dini (ada) & 5.62 & 2.63 & 8.62 & $<0.001^{*}$ \\
\hline Pendapatan( $(\geq \mathrm{UMR})$ & -1.58 & -3.11 & -0.06 & $0.042^{*}$ \\
\hline Persepsi (setuju) & 2.75 & 0.49 & 5.02 & $0.017^{*}$ \\
\hline \multicolumn{5}{|l|}{ Indirect } \\
\hline $\begin{array}{l}\text { Emotional insecurity } \leftarrow \\
\text { Disharmoni keluarga (tinggi) }\end{array}$ & 1.30 & 0.51 & 2.08 & $0.001^{*}$ \\
\hline Disharmonikeluarga (tinggi) & 0.93 & 0.04 & 1.82 & $0.040^{*}$ \\
\hline Sikap pergaulan bebas (tinggi) & 2.04 & 1.08 & 3.00 & $<0.001^{*}$ \\
\hline \multicolumn{5}{|l|}{ Pergaulan bebas $\leftarrow$} \\
\hline $\begin{array}{l}\text { Emotional insecurity (tinggi) } \\
\text { Pendapatan }(\geq \mathrm{UMR}) \leftarrow\end{array}$ & 1.38 & 0.58 & 2.18 & $0.001^{*}$ \\
\hline Pendidikan ( $\geq$ SMA) & 3.47 & 2.20 & $4 \cdot 74$ & $<0.001^{*}$ \\
\hline Pendapatan (tinggi) & -2.03 & -2.86 & -1.21 & $<0.001^{*}$ \\
\hline \multicolumn{5}{|l|}{$\begin{array}{l}\text { N Observasi }=120 \\
\text { Log likelihood }=-356.66\end{array}$} \\
\hline $\begin{array}{l}\mathrm{AIC}=745 \cdot 31 \\
\mathrm{BIC}=789.91\end{array}$ & $\begin{array}{l}\text { Keteran } \\
\leftarrow \mathrm{Me}\end{array}$ & $\begin{array}{l}\text { 1: } \\
\text { engaruhi }\end{array}$ & & \\
\hline
\end{tabular}

Pada Tabel 3 menunjukkan faktor yang berhubungan langsung dan tidak langsung dengan terjadinya pernikahan dini. Faktor yang berhubungan langsung dengan pernikahan dini adalah KTD, budaya lokal menikah dini, tingkat pendapatan dan persepsi orang tua tentang menikah dini. Sedangkan untuk faktor yang berhubungan tidak langsung dengan terjadinya pernikahan dini adalah disharmoni keluarga, emotional insecurity, sikap kecenderungan melakukan pergaulan bebas, dan pendidikan ibu. Nilai koefisien regresi yang ditunjukkan Tabel 3 telah bernilai lebih dari nol dan secara statistik sudah signifikan, hal ini menunjukkan bahwa model yang dibuat pada path analysis (gambar 1) telah sesuai dengan data sampel yang ada sehingga tidak perlu membuat ulang model path analysis. Pada tabel tersebut juga ditunjukkan log likehood=-356.66 dengan $\mathrm{N}$ observasi $=120$.

\section{PEMBAHASAN \\ 1. Hubungan antara Disharmoni Keluarga dan Terjadinya Perni- kahan Dini}

Hasil analisis menunjukkan bahwa ada hubungan tidak langsung antara disharmoni keluarga dan terjadinya pernikahan dini melalui variabel antara emotional insecurity, sikap kecenderungan melakukan pergaulan bebas, dan KTD. Hubungan bersifat positif dan signifikan. Remaja yang mengalami disharmoni keluarga tinggi memiliki kenaikan logit risiko untuk melakukan pernikahan dini.

Hasil penelitian menunjukkan bahwa sebagian besar remaja menikah dini mengalami disharmoni keluarga tinggi. Dari subjek penelitian didapatkan bahwa kebanyakan orang tua sibuk sebagai buruh tani ataupun pedagang sehingga kontrol kepada anak sangat kurang. Faktor lain adalah orang tua kurang memberi perhatian walaupun sebenarnya ibu tidak bekerja di luar 
Journal of Health Promotion and Behavior (2016), 1(2): 87-98

https://doi.org/10.26911/thejhpb.2016.01.02.04

rumah, namun orang tua yang memberi kepercayaan penuh pada anak tanpa ada kontrol dapat menyebabkan terjadinya KTD sehingga pernikahan dini tidak dapat dihindari.

Hal ini sejalan dengan teori Talcott Parsons bahwa tindakan dapat dipengaruhi oleh sistem sosial, dalam hal ini adalah interaksi antara anak dan orang tua. Disharmoni keluarga menjadikan anak kekurangan sarana untuk pengembangan kreativitas dan memuaskan kebutuhan anak. Se hingga anak cenderung mencari kepuasan di luar rumah, dan keluar dari sistem yang seharusnya (Raho, 2007).

Hasil penelitian ini sesuai dengan penelitian yang dilakukan oleh Blanco, et al (2012) yang menyatakan bahwa meningkatnya fungsi keluarga akan sangat berguna untuk kesejahteraan psikologis anak, hal ini dapat dicapai dengan mempromosikan peran gender pada anak perempuan. Dari hasil penelitian melalui kuesioner tentang disharmonis keluarga, sebagian besar remaja pada kelompok kasus berpendapat tidak ada musyawarah secara kekeluargaan jika ada masalah dalam keluarga dan remaja juga berpendapat tidak akan meminta pendapat atau bantuan orangtua jika mempunyai masalah. Hasil tersebut menunjukkan bahwa masih kurang terlaksananya fungsi keluarga untuk anak sehingga anak lebih memilih berbagi dengan teman.

Hasil penelitian Rusmilawaty, Yuni arti dan Tunggal (2016) menyatakan bahwa komunikasi orangtua sangat penting untuk remaja terutama untuk mencegah remaja melakukan perilaku seks bebas. Hasil penelitiannya membuktikan bahwa orang tua yang selalu membangun komunikasi baik dan mengawasi anak dapat menurunkan risiko perilaku seksual pada anak remaja. Hasil ini berarti mendukung hasil penelitian yang telah dilakukan peneliti bahwa keluarga yang harmonis dapat menurunkan terjadinya pernikahan dini melalui penurunan seksual remaja sehingga kehamilan tidak diinginkan juga dapat berkurang.

Berdasarkan hal tersebut maka dapat disimpulkan bahwa ada hubungan antara disharmoni keluarga dan terjadinya pernikahan dini. Dengan demikian hasil sesuai dengan penelitian terdahulu dan teori yang ada.

\section{Hubunganantara Emotional Inse curity dan Terjadinya Pernikahan Dini}

Hasil analisis menunjukkan bahwa ada hubungan tidak langsung antara emotional insecurity dan terjadinya pernikahan dini melalui variabel antara pergaulan bebas, dan KTD. Hubungan bersifat positif dan signifikan.

Hasil penelitian menunjukkan kebanyak remaja yang memiliki emotional insecurity tinggi berasal dari keluarga yang disharmoni keluarga tinggi. Disharmoni ke luarga menjadikan remaja merasa kurang percaya diri dalam pergaulan di masyarakat. Hal ini dapat mempengaruhi perkembangan psikologis anak. Sesuai dengan teori tindakan Talcott Parsons bahwa tindakan dapat terjadi karena sistem kepribadian, sistem kepribadian dapat dikendalikan oleh sistem sosial yaitu keluarga, masyarakat, pertemanan di lingkungan rumah ataupun sekolah. Sehingga keadaan emotional insecurity tinggi pada anak jelas mempengaruhi tindakan yang akan dilakukan oleh anak itu sendiri salah satunya adalah pernikahan dini.

Faktor lain yang mendorong ter jadinya pernikahan dini adalah responsosial, emosional dan kebutuhan seksual re maja. Para remaja melihat pernikahan sebagai cara untuk mencapai kemerdekaan dan identitas sosial sebagai bagian penting dari transisi remaja ke dewasa. Terutama pada remaja yang merasa terabaikan oleh orang tua akan mencari tempat yang bisa 
melindungi dan memperhatikan kebutuhannya sehingga mungkin terjerumus ke dalam pergaulan dengan lingkungan yang secara normatif tidak baik tetapi menurut remaja tersebut memberikan kedamaian tidak terkecuali dengan melakukan pernikahan dini (Omarsari dan Djuwita, 2008; Karismawati dan Lukitaningsih, 2013).

Berdasarkan hal tersebut dapat disimpulkan bahwa ada hubungan antara emotional insecurity dan terjadinya pernikahan dini. Dengan demikian hasil sesuai dengan penelitian terdahulu dan teori yang ada.

\section{Hubungan antara Sikap Kecende rungan Melakukan Pergaulan Be- bas dan Terjadinya Pernikahan Dini}

Hasil analisis menunjukkan bahwa ada hubungan tidak langsung antara sikap ke cenderungan melakukan pergaulan bebas dan terjadinya pernikahan dini melalui variabel antara KTD. Hubungan bersifat positif dan signifikan.

Dari pertanyaan kuesioner penelitian tentang sikap kecenderungan melakukan pergaulan bebas yang telah diajukan, Sebagian besar kelompok kasus berpendapat merasa nyaman jika bermain dengan teman hinggalarut malam, sering berselisih faham dengan teman, dan orangtua tidak mengenal dengan siapa saja remaja bergaul. Hal ini dapat menyebabkan kontrol pada remaja kurang sehingga sikap kecenderungan melakukan pergaulan bebas tinggi.

Hasil penelitian sesuai dengan teori Talcott Parsons bahwa masyarakat akan melakukan empat hal untuk keberlangsungan dan menjalankan fungsinya salah satunya adalah dengan adaptasi. Adaptasi dilakukan masyarakat sebagai cara untuk menanggulangi situasi eksternal yaitu dengan penyesuaian diri dengan lingkungan. Namun dengan kontrol yang minim dari orangtua, remaja dapat mengikuti adaptasi lingkungan dengan cara yang tidak benar yaitu pergaulan bebas (Ritzer dan Douglas, 2010).

Hasil penelitian ini sesuai dengan hasil penelitian yang dilakukan oleh Fagbamigbe et al.,(2016) yang menyatakan bahwa pergaulan teman sebaya sebagai salah satu faktor pembentuk sikap dan perilaku remaja. Beberapa kelompok sebaya menekan remaja perempuan untuk melakukan kegiatan seperti minum alkohol dan merokok, oleh karena itu mereka cenderung mulai melakukan hubungan seksual dini dan akhirnya kehamilan dan pernikahan tidak dapat dibatalkanlagi.

Berdasarkan hal tersebut maka dapat disimpulkan bahwa ada hubungan antara sikap kecenderungan melakukan pergaulan bebas dan terjadinya pernikahan dini. Dengan demikian hasil sesuai dengan penelitian terdahulu dan teori yang ada.

\section{Hubungan antara Kehamilan Ti- dak Diinginkan dan Terjadinya Pernikahan Dini}

Hasil analisis menunjukkan bahwa ada hubungan langsung antara KTD dan terjadinya pernikahan dini. Hubungan bersifat positif dan signifikan. Remaja yang mengalami KTD memiliki kenaikan logit risiko untuk melakukan pernikahan dini.

Dari pertanyaan kuesioner tentang KTD, sebagian besar remaja pada kelompok kasus menjawab bahwa remaja tidak segera memeriksakan diri ke fasilitas kesehatan ketika mengalami telat datang bulan. Selain itu remaja pada kelompok kasus sebagian besar tidak mengetahui tentang sejumlah bahaya yang mungkin terjadi pada kehamilan di usia muda.

Menurut Talcott Parsons, sistem kepribadian tidak dapat berdiri sendiri, sistem kepribadian dipengaruhi oleh sistem sosial dan kultural. Kepribadian adalah sistem motivasi yang ada dalam diri individu yang mempunyai tujuan untuk memenuhi kebutuhan. Kebutuhan tersebut bukanlah 
Journal of Health Promotion and Behavior (2016), 1(2): 87-98

https://doi.org/10.26911/thejhpb.2016.01.02.04

dorongan naluriah yang muncul sejak lahir, namun kebutuhan ini muncul karena adanya setting sosial. Kehamilan tidak diinginkan yang terjadi pada subjek penelitian merupakan setting sosial yang karenanya remaja melakukan pernikahan dini. Sebagian remaja akan malu, terhenti pendidikan hingga terganggu psikologisnya jika mengalami kehamilan tanpa dukungan suami. Sehingga untuk menyelesaikan masalah tersebut sistem dalam hal ini orangtua atau masyarakat setempat akan segera menikah kan remaja walaupun masih dibawah umur (Raho, 2007).

Hasil penelitian ini sesuai dengan penelitian yang dilakukan oleh Karjono dan Murtiananingsih (2014) yang menyatakan bahwa kehamilan tidak diinginkan merupa kan faktor pendukung yang menyebabkan remaja melakukan pernikahan dini di Daerah Pesisir Pantai Kuta Kabupaten Lombok Tengah.

Temuan lain dari hasil penelitian ini adalah beberapa kerugian kesehatan yang muncul akibat dari kehamilan dan persalinan di usia muda. Kerugian tidak bersifat fatal namun cukup mempengaruhi kesehatan ibu dan bayi. Dari segi kesehatan ibu, anemia adalah salah satu kerugian yang paling banyak dirasakan oleh ibu hamil diusia muda. Selain anemia, satu atau beberapa remaja yang menikah dini mengalami partus lama, bendungan asi dan penyakit menular seksual yaitu gonorrhea. Dari segi kesehatan bayi, kerugian paling banyak dirasakan oleh bayi adalah ikterik patologis, berat lahir rendah, dan cakupan ASI eksklusif yang sangat kurang.

Berdasarkan hal tersebut maka dapat disimpulkan bahwa ada hubungan antara kehamilan tidak diinginkan dan terjadinya pernikahan dini. Dengan demikian hasil sesuai dengan penelitian terdahulu dan teori yang ada.

\section{Hubungan antara Pendidikan Ibu dan Terjadinya Pernikahan Dini}

Hasil analisis menunjukkan bahwa ada hu bungan tidak langsung antara pendidikan ibu dan terjadinya pernikahan dini melalui variabel antara tingkat pendapatan dan persepsi orangtua tentang menikah dini. Hubungan bersifat positif dan signifikan. Hasil dari penelitian ini, sebagian besar subjek penelitian memiliki ibu dengan pendidikan rendah.

Pendidikan ibu berperan penting dalam pengembangan kemampuan, pembentukan watak dan membentuk anak agar beradab mulia dan bermartabat karena lingkungan keluarga adalah sebagai lingkungan pendidik pertama pada anak. Pendidikan ibu yang baik dapat menciptakan lingkungan keluarga yang baik juga, sebaliknya jika pendidikan ibu rendah akan sulit menciptakan lingkungan yang baik dalam keluarga. Sebagian besar anak dengan ibu berpendidikan rendah kurang termotivasi untuk melanjutkan pendidikan ke jenjang lebih tinggi selain itu ibu dengan pendidikan rendah tidak mampu memberikan pendidikan kesehatan reproduksi pada anak sehingga hal ini dapat menyebabkan terjadinya pernikahan dini. Situasi ini menandakan bahwa keluarga sebagai sistem tidak mampu menjalankan fungsinya dengan baik dan tidak dapat memberi kontrol pada anak sebagai aktor (pelaku) (Raho, 2007).

Hasil penelitian ini sesuai dengan hasil penelitian yang dilakukan oleh Smith, et al (2012) yang menyatakan bahwa pendidikan seorang ibu memainkan peran penting untuk menunda pernikahan dini pada anak. Pendidikan keaksaraan pada anak perempuan terbukti berhubungan erat dengan penundaan menikah di usia muda pada diri sendiri dan anak perempuan mereka kelak. 
Hasil penelitian ini juga sesuai dengan hasil penelitian Rafidah et al (2014) yang menyatakan bahwa ada hubungan yang bermakna antara pendidikan orangtua dan pernikahan usia dini. Pendidikan merupakan salah satu faktor yang mempengaruhi persepsi seseorang, dengan pendidikan tinggi seseorang akan lebih mudah menerima atau memilih suatu perubahan yang lebih baik. Rendahnya tingkat pendidikan orangtua mendorong percepatan keputusan untuk segera menikahkan anak-anaknya walaupun masih dibawah umur karena rendahnya tingkat pendapatan sehingga tidak mampu untuk membiayai kelanjutan pendidikan anak.

Berdasarkan hal tersebut maka dapat disimpulkan bahwa ada hubungan antara pendikan orangtua dan terjadinya pernikahan dini. Dengan demikian hasil sesuai dengan penelitian terdahulu dan teori yang ada.

\section{Hubungan antara Tingkat Penda- patandanTerjadinyaPernikahan Dini}

Hasil analisis menunjukkan bahwa ada hubungan langsung antara tingkat pendapatan dan terjadinya pernikahan dini. $\mathrm{Hu}-$ bungan bersifat positif dan signifikan. Remaja yang tinggal dengan keluarga tingkat pendapatan tinggi memiliki penurunan logit risiko untuk melakukan pernikahan dini.

Sesuai dengan teori dariSoetjiningsih (2004) yang menyatakan bahwa anak yang tumbuh di lingkungan pendapatan yang cukup akan dapat memberikan sarana dan prasaran yang cukup untuk anak, sehingga kebutuhannya dapat tercukupi. Hal ini berkaitan dengan kondisi remaja yang serba kekurangan akan mendorong remaja mencukupikebutuhantersebut,salah satunya adalah dengan melakukan pernikahan dini. Dengan harapan calon suaminya dapat memenuhi kebutuhannya.
Hasil dari penelitian yang dilakukan memperlihatkan bahwa kondisi tingkat pendapatan yang rendah berkaitan erat dengan rendahnya kontrol orangtua terhadap anak. Kesibukan orangtua sebagai seorang buruh atau karyawan swasta diluar rumah menjadikan orangtua tiak dapat mengontrol kegiatan anak sehari-hari. Ditunjang dengan pendidikan yang rendah dari orangtua menjadikan orangtua tidak terlalu mempunyai banyak cara untuk mengontrol dan menjaga kegiatan anak sehari-hari. Hal ini dapat terlihat pada hasil wawancara dari kuesioner pendapatan, sebagian besar kelompok kasus memiliki tingkat pendapatan rendah dibanding dengan kelompok kontrol.

Penelitian ini sesuai dengan hasil penelitian yang dilakukan oleh Rafidahet al (2009) yang menyatakan bahwa anak yang memiliki ekonomi keluarga rendah berisiko 1,75 kali lebih besar untuk menikah pada usia <20 tahun dibanding dengan anak yang memiliki ekonomi keluarga tinggi. Tingkat pendapatan yang rendah tidak menjamin kelangsungan pendidikan anak sehingga apabila seorang anak perempuan telah menamatkan pendidikan dasar atau pendidikan wajib sembilan tahun dan tidak melanjutkan ke jenjang pendidikan tinggi, ia hanya tinggal di rumah. Sehingga banyak dari responden remaja yang memilih menikah di usia muda adalah untuk meringankan beban hidup orangtua.

Berdasarkan hal tersebut maka dapat disimpulkan bahwa ada hubungan antara tingkat pendapatan dan terjadinya pernikahan dini.Dengan demikian hasil sesuai dengan penelitian terdahulu dan teori yang ada.

\section{Hubungan antara Persepsi OrangtuaTentangMenikah Dini dan Terjadinya Pernikahan Dini}

Hasil analisis menunjukkan bahwa ada hubungan langsung antara persepsi orang 
Journal of Health Promotion and Behavior (2016), 1(2): 87-98

https://doi.org/10.26911/thejhpb.2016.01.02.04

tua dan terjadinya pernikahan dini. Hubungan bersifat positif dan signifikan. Persepsi kemampuan diri ibu menjadi determinan yang paling berpengaruh terhadap perilaku ibu dalam memberikan pendidikan seksulitas kepada anak remaja.

Dari kuisioner yang digunakan dalam penelitian menunjukkan bahwa persepsi orangtua, dalam hal ini diwakili oleh ibu responden sebagian besar berpendapat bahwa menikahkan anak adalah hal yang baik dari pada anak melakukan seks sebelum menikah walaupun anak masih dibawah umur. Menurut mereka jika anak telah datang masa haid berarti anak telah siap untuk hamil dan melahirkan, sehingga menikahkan anak diusia muda bukanlah hal yang buruk atau membahayakan kesehatan.

Menurut Rakhmat (2005), menyatakan bahwa persepsi dipengaruhi oleh faktor dari dalam diri individu sendiri dan faktor situasional. Persepsi tentang menikah dini di penelitian ini sebagian besar terbentuk dari situasi keluarga dengan pendapatan rendah dan pendidikan rendah sehingga membentuk persepsi setuju terhadap menikah dini, sebagai cara untuk mempertahankan diri dari lingkungan yang ada. Menurut Talcott Parsons, sebuah sistem harus dapat beradaptasi terhadap lingkungan untuk dapat mencapai tujuan utama.Dalam penelitian ini, keluarga dengan tingkat pendapatan rendah beradaptasi dengan lingkungan dengan cara menikahkan dini anak perempuannya. Tujuannya adalah agar anak perempuan yang tidak bisa melanjutkan pendidikan dapat berkegiatan sebagai ibu rumah tangga (Ritzer dan Douglas, 2010).

Hasil penelitian ini sesuai dengan penelitian yang dilakukan oleh Montazeri et al (2016) yang menyatakan bahwa keluarga di Iran memiliki persepsi dan sikap positif terhadap pernikahan dini atas dasar nilai tradisi yang ada. Negara Iran melarang se cara hukum dan moral terhadap perbuatan seksual diluar nikah. Orang tua akan me milih menikahkan anak perempuan mereka untuk mencegah perilaku seksual diluar nikah karena keterpaparan anak terhadap media yang merangsang remaja melalui gambar visualerotis, musik dan film porno.

Berdasarkan hal tersebut maka dapat disimpulkan bahwa ada hubungan antara persepsi orangtua tentang menikah dini dan terjadinya pernikahan dini. Dengan demikian hasil sesuai dengan penelitian terdahulu dan teori yang ada.

\section{Hubungan antara Budaya Lokal Menikah Dini dan Terjadinya Per- nikahan Dini}

Hasil analisis menunjukkan bahwa ada hubungan langsung antara budaya lokal me nikah dini dan terjadinya pernikahan dini. Hubungan bersifat positif dan signifikan. Remaja yang tinggal di lingkungan dengan budaya lokal menikah dini memiliki peningkatan logit risiko untuk melakukan per nikahan dini.

Dari pertanyaan kuesioner tentang budaya lokal menikah dini sebagian besar remaja berpendapat bahwa pernikahan di usia sebelum 20 tahun adalah hal yang wajar. Kebanyakan keluarga dari remaja di kelompok kasus juga mendukung dengan pernikahan dini yang dilakukan. Menurut Kusujiarti (1995) dalam Hanum (1997) menyatakan bahwa masyarakat Jawa mengenal tiga macam pernikahan jika dilihat dari sudut perjodohan. Hasil penelitian yang telah dilakukan didapatkan bahwa sebagian besar remaja yang menikah tergo long dalam mixed marriage, yaitu pernikahan yang dilakukan atas dasar keputusan orangtua namun masalah jodoh diserahkan pada anak.

Talcott Parsons (dalam Raho, 2007) menyatakan bahwa kebudayaan sebagai unit yang paling dasar dari sebuah tinda- 
kan. Hal ini disebabkan karena di dalam kebudayaan terdapat norma dan nilai yang harus ditaati oleh individu untuk mencapai tujuan dari kebudayaan itu sendiri. Pernikahan dini yang dilakukan oleh remaja disebabkan oleh berbagai alasan antara lain norma sosial pada masyarakat Jawa yang menganggap pentingnya keperawanan pa da remaja putri. Sehingga pernikahan dini dianggap satu-satunya cara untuk menyelamatkan anak dari seks bebas, agar kepera wanan anak tetap terjaga.

Hal ini sesuai dengan teori yang dikemukakan oleh ICRW (2010) bahwa dalam banyak masyarakat, orangtua berada dibawah tekanan untuk segera menikahkan anak perempuan sedini mungkin dalam upaya mencegah anak dari menjadi aktif secara seksual sebelum pernikahan. Aktif secara seksual sebelum menikah membawa pencemaran untuk keluarga dan masyarakat. Hal ini juga yang banyak terjadi di tempat penelitian yaitu Kabupaten Sleman. Sehingga banyak orangtua yang memilih menikahkan anak perempuan sedini mungkin untuk mencegah seksual aktif diluar nikah ataupun karena mencegah pencemaran nama keluarga karena telah mengalami kehamilan diluar nikah.

Berdasarkan hal tersebut maka dapat disimpulkan bahwa ada hubungan antara budaya lokal menikah dini dan terjadinya pernikahan dini. Dengan demikian hasil sesuai dengan penelitian terdahulu dan teori yang ada.

Penelitian ini menyimpulkan ada hubungan disharmoni keluarga, emotional insecurity, sikap kecenderungan melakukan pergaulan bebas, kehamilan tidak diinginkan, pendidikan ibu, tingkat pendapatan, persepsi orangtua tentang menikah dini, dan budaya lokal menikah dini dengan terjadinya pernikahan dini di Kabupaten Sleman.
DAFTAR PUSTAKA

Antenna Foundation Nepal (AFN) (2016). Violence Against Women and Girls. http://www.afn.org.np/GenderSite.as px. Diakses pada 9 Juny 2016

Badan Kependudukan dan Keluarga Berencana Nasional (BKKBN). (2010). Penyiapan Kehidupan Berkeluarga Bagi Remaja. Jakarta: Direktorat Remaja dan Perlindungan Hak-hak Reproduksi

Blanco EIL,Unger JB, Garbanati LB, Olson AR, Soto D (2012). Acculturation, Enculturation, and Symptoms of Depression in Hispanic Youth: The Roles of Gender, Hispanic Cultural Values, and Family Functioning. J. Youth Adolesc. 41 (10): 1350-1365.

Fagbamigbe AF, Idemudia ES (2016). Survival Analysis And Prognostic Factors Of Timing Of First Childbirth Among Women In Nigeria. BMC Pregnancy and Childbirth. 16 (102): 112.

Hanum SH (1997). Perkawinan Usia Belia. Yogyakarta: Pusat Penelitian Kependudukan, Universitas Gadjah Mada.

Internasional Center for Research on Women (ICRW) (2010). The Causes, Consequences and Solutions to Forced Child Marriage in The Developing World. www.icrw.org. Diakses pada 28 Juni 2016

Karismawati, Lukitaningsih (2013). Studi Tentang Faktor-Faktor yang Mendorong Remaja Melakukan Pernikahan Dini di Kecamatan Kemlagi Kabupaten Mojokerjo. Journal Mahasiswa Bimbingan Konseling. 01(01): 44-49.

Karjono, Murtiananingsih (2014). Penyebab Terjadinya Pernikahan Dini Pada Remaja di Daerah Pesisir Pantai Kuta Kabupaten Lombok Tengah. Media Bina Ilmia. 8 (7): 34-37. 
Journal of Health Promotion and Behavior (2016), 1(2): 87-98

https://doi.org/10.26911/thejhpb.2016.01.02.04

Kasi Bimas Islam Kantor Kementerian Agama Kabupaten Sleman (2016). Laporan Data NTCR Tahun 2015. Sleman: Kantor Kementerian Agama Kabupaten Sleman.

Koentjaraningrat (1994). Kebudayaan Mentalitas dan Pembangunan. Jakarta: Gramedia Pustaka Utama.

Montazeri S, Gharacheh M, Mohammadi N, Rad JA, Ardabili HE (2016) Determinants of Early Marriage from Married Girls' Perspectives in Iranian Setting: A Qualitative Study. Journal of Environmental and Public Health. $1(8)$.

Mutyaba (2011). Early Marriage: A Violation of Girls' Fundamental Human Rights in Africa. International Journal of Children's Right. 19: 339-355.

Omarsari, Djuwita (2008). Kehamilan Pranikah Remaja di Kabupaten Sumedang. KESMAS, Jurnal Kesehatan Masyarakat Nasional. 3(2) 57-64.

Prakarsa (2013). Angka Kematian Ibu (AKI) Melonjak, Indonesia Mundur 15 Tahun. www.theprakarsa.org. Diakses pada 20 Maret 2014

Pusat Data dan Informasi Kemenkes. (2014). Situasi Kesehatan Ibu. www.depkes.go.id. Diakses pada 9 Juni 2016.
Rafidah (2009). Faktor yang Berhubungan dengan Pernikahan Dini di Kabupaten Purworejo Jawa Tengah. Berita Kedokteran Masyrakat. 25(2): 51-58.

Rahmat J (2005). Psikologi Komunikasi. Bandung: Remaja Rosdakarya.

Raho, Bernard SVD (2007). Teori Sosiologi Modern. Jakarta: Prestasi Pustaka.

Ritzer G, Douglas JG (2010). Teori Sosiologi Modern. Kencana: Jakarta.

Rusmilawaty, Yuniarti, Tunggal T (2016). Communication of Parents, Sexual Content Intake and Teenege Sexual Behavior at Senior High Shcool in Banjarmasin City. Kesmas Jurnal Kesehatan Masyarkat Nasional. 10 (3): 113-119.

Smith, Stone, Kahando (2012). A Model of Women's educational Factor Related to Delaying Girls' Marriage. International Review of Education. 58: 533-555.

Soetjiningsih (2004). Tumbuh Kembang Anak. Jakarta: EGC

United Nations, Departement of Economic and Social Affairs (2011). World Fertility policies 2011. United Nations Publication, Sales Nomor. E.11.XIII.5

UNICEF (2013). Child Marriages: 39.000 Every day. www.unicef.org. Diakses pada 9 Juni 2016 